\title{
Publisher Correction: Observation of transverse spin Nernst magnetoresistance induced by thermal spin current in ferromagnet/non-magnet bilayers
}

Dong-Jun Kim¹, Chul-Yeon Jeon ${ }^{1}$, Jong-Guk Choi ${ }^{1}$, Jae Wook Lee ${ }^{1}$, Srivathsava Surabhi ${ }^{2}$, Jong-Ryul Jeong ${ }^{2}$, Kyung-Jin Lee Le $^{3,4}$ \& Byong-Guk Park ${ }^{1}$

Correction to: Nature Communications https://doi.org/10.1038/s41467-017-01493-5, Article published online 9 November 2017

The original version of this Article contained an error in ref. ${ }^{27}$, which was incorrectly given with the wrong journal name as:

Meyer, S. et al. Observation of the spin Nernst effect. Nat. Phys. 16, 977-981 (2017).

The correct form of ref. ${ }^{27}$ is:

Meyer, S. et al. Observation of the spin Nernst effect. Nat. Mater. 16, 977-981 (2017).

This has now been corrected in the PDF and HTML versions of the Article.

Published online: 05 January 2018

\footnotetext{
(c) (i) Open Access This article is licensed under a Creative Commons Attribution 4.0 International License, which permits use, sharing, adaptation, distribution and reproduction in any medium or format, as long as you give appropriate credit to the original author(s) and the source, provide a link to the Creative Commons license, and indicate if changes were made. The images or other third party material in this article are included in the article's Creative Commonslicense, unless indicated otherwise in a credit line to the material. If material is not included in the article'sCreative Commons license and your intended use is not permitted by statutory regulation or exceeds the permitted use, you will need to obtain permission directly from the copyright holder. To view a copy of this license, visit http://creativecommons.org/licenses/by/4.0/.
}

(c) The Author(s) 2017

\footnotetext{
${ }^{1}$ Department of Materials Science and Engineering and KI for Nanocentury, KAIST, Daejeon 34141, Korea. ${ }^{2}$ Department of Materials Science and Engineering, Graduate School of Energy Science Technology, Chungnam National University, Daejeon 34134, Korea. ${ }^{3}$ Department of Materials Science and Engineering, Korea University, Seoul 02841, Korea. ${ }^{4}$ KU-KIST Graduate School of Converging Science and Technology, Korea University, Seoul 02841, Korea. Correspondence and requests for materials should be addressed to B.-G.P. (email: bgpark@kaist.ac.kr)
} 